\title{
The challenge and opportunities of thailand education due to the covid-19 pandemic: case study of Nakhon Pathom, Thailand
}

\author{
Yingsak Vanpetch ${ }^{1, *}$, Mahachai Sattayathamrongthian ${ }^{2}$ \\ ${ }^{1}$ International College, Suan Sunandha Rajabhat University, Bangkok, Thailand \\ ${ }^{2}$ Rajamangala University of Technology Rattanakosin, Salaya, Phutthamonthon, NakhonPathom, \\ Thailand
}

\begin{abstract}
This research aims to define the challenges and opportunities and how educational staff, teacher, lecturer in Nakhon Pathom, and Thailand respond to the disruptive impact of the COVID-19 pandemic, and understand the education obstacles due to the Covid19 pandemic in Nakhon Pathom, Thailand. The information was collected by in-depth interview with 28 experienced educational staff in Nakhon Pathom, Thailand, using snowball sampling during April 2020.Scope of information on the education obstacles, the challenges, and opportunities and how educational staff, teacher, lecturer in Nakhon Pathom, and Thailand respond to the disruptive impact of the COVID-19 pandemic. The data was analyzed using cause and effect analysis. The observed obstacles using the qualitative research methodology would be defined in the literature review section. The education obstacles due to the Covid19 pandemic are educational staff social impacts, educational staff working impacts, institutional responses, and support in resources. The study can be concluded that every crisis, there is always an opportunity. Perhaps, in this case, it is an opportunity for a pedagogical review. Therefore, it is expected that much educational staff will undertake the path of a necessary pedagogical renewal that favours both quality and equality. It is necessary to start from the principle of realism and generate strategies that do not rely only on a single technology, but on several to ensure that all students are taken into account or, which is equally or more critical, that technological solutions do not harm those who are already disadvantaged
\end{abstract}

\section{Introduction}

Due to the COVID-19 pandemic, there has been a significant decrease in learning activities and the workforce's restriction to essential personnel in Thailand education. Thailand's education has faced a significant obstacle, with many institutions limiting offline training and lecturer. In the setting of social distancing, most of the teaching sessions have moved to virtual classrooms and lectures. Online education using a program such as a zoom, Google classroom, or freely available software has shown the potential efficacy of

* Corresponding author: yingsak.va@ssru.ac.th 
remote learning within Thailand education. The COVID-19 pandemic has moved our locale to consider adjusting the training framework's requirements for future practice.The utilization of innovation can alleviate a portion of the adverse effects of diminished disconnected preparing presentation, and in the period of social removing, projects should keep on creating virtual educational plans for preparing training. Nonetheless, there is still the opportunity to get better in guaranteeing students get sufficient instruction and preparing to plan for their future vocations during this pandemic.

Nakhon Pathom, with a population of almost 900,000, is a small province located $56 \mathrm{~km}$ west of Bangkok. The area of Nakhon Pathom is 2,168,327 square kilometres, and most of it consists of plains with no mountainous land. The plains along the Tha Cheen River (also called Nakhon Chaisi River) are fertile and provide agricultural opportunities. In this study, the researchers observe the information from educational staff, teachers, and lecturer who work in Nakhon Pathom, Thailand, to define the new changes in Thailand education.

\section{Research Question and objective}

How the COVID -19 will significantly affect on the Thailand Education?

Research Objective - to understand the education obstacles due to the Covid19 pandemic in Nakhon Pathom, Thailand; to define the challenges and opportunities and how educational staff, teacher, lecturer in Nakhon Pathom, and Thailand respond to thedisruptive impact of the COVID-19 pandemic.

\section{Literature Review}

\subsection{Thailand Formal Education}

Formal education administrations are classified into Early Year Education, Basic Education, Vocational and Technical Education, and Higher Education. Early Year Education Over $74 \%$ of kids, matured 3 to 5 get youth education. Primary education in Thailand is divided into six years of primary schooling (Grade 1 to 6), followed by three years of lower secondary (Grade 7 to 9) and three years of upper secondary schooling (Grade10 to 12). Eight center subjects structure the National Curriculum: Thai language, arithmetic, science, social studies, religion and culture, health and physical education, careers and technology, and foreign languages. Adaptability is incorporated with the educational program to coordinate neighborhood astuteness and culture, so it is steady with set learning guidelines in every one of the center subject gatherings. The advancement of reasoning aptitudes, self-learning procedures, and functional improvement is at the core of educating and learning in the Thai National Curriculum.

\subsection{Vocational and Technical Education}

Formal vocational and technical education is directed at three levels: upper secondary, postsecondary, and university level [1]. There are, as of now, more than 1 million students enrolled in various vocational study pathways. Eight fields of study are embraced as majors: exchange and industry, horticulture, home financial matters, fisheries, business, travel industry, expressions and artworks, materials, and trade. The advance toward deeprooted learning and a learning society has been encapsulated in a credit move framework to encourage portability between foundations; in acknowledgment of various kinds of capabilities from different establishments offering professional preparing; and the assessment of earlier taking in and work understanding from inside the formal, non-formal 
and casual areas [2]. At present, changes are being executed to redesign the framework towards a Thai Vocational Qualification (TVQ) because of machining practices and needs.

\subsection{Higher education}

The method for student admission to the high education segment is the high School Entrance examination taken toward the finish of Grade 12. Late changes have expanded the significance set on Grade Point Averages (GPA) for a particular college passage. Advanced education is transcendently given at colleges and schools. The two unmistakable degrees of instructive achievement is the recognition level and advanced educations. Over 2.2 million students have now taken on the advanced education area, and investment paces of collegeage studentshave expanded fundamentally in the course of the most recent couple of years, from a normal of $26 \%$ to the current normal of $40 \%$ [3]. Lately, there has been a critical increment in advanced education openings with 78 state-funded colleges and 89 private higher education institutions.

\subsection{COVID-19 International Situation (Department of Disease Control, 2020)}

As of August 4, 2020, there were 18,463,215 affirmed cases with 64,679 patients in basic condition and 697,730 COVID-19 passing across more than 210 nations, two Special Administrative Regions of the People's Republic of China (Hong Kong and Macau), and on journey ships. The ten nations with the most affirmed COVID-19 cases include: The United States $(4,862,285)$, Brazil $(2,751,665)$, India $(1,858,689)$, Russia $(861,423)$, South Africa (516,862), Mexico (443,813), Peru (433,100), Chile (361,493), Spain $(344,134)$, and Colombia $(327,850)$. The 29 th is the People's Republic of China $(88,102$ cases, 3,592 , and 46 cases in the Special Administrative Regions of Hong Kong and Macau, separately).

Table 1. COVID-19 Thailand Situation (Department of Disease Control, 2020).

\begin{tabular}{|l|l|}
\hline Confirmed cases & 3321 \\
\hline - Recovered and discharged from hospitals & 3142 \\
\hline -Undergoing Treatment & 121 \\
\hline -Deaths & 58 \\
\hline Characteristics of Infection in Confirmed cases & 3321 \\
\hline -Local Transmission & 2444 \\
\hline -Imported Cases & 877 \\
\hline Designated Quarantine Places* & 384 \\
\hline
\end{tabular}

Notice: Quarantine measures for travelers from abroad have been in effect since April 3, 2020.

The median age of the confirmed cases is 37 years old (ranging from 1 month to 97 years old). One thousand eight hundred forty-eight cases are male, and 1,473 are female (male to female ratio is 1.23:1). In terms of nationality, 2,979 cases are Thai, 333 are foreigners, and data is not available for the remaining 9 cases.

Two hundred six cases were reported with underlying diseases, and 3,115 cases reported without any underlying disease. Forty cases were detected from the screening protocol at airports (one case was found within the group of Thai workers returning from Wuhan). One thousand five hundred eighty-eight cases sought medical treatment by themselves; 1,189 were tracked via case investigation and defined as "close contacts." A total of 55 confirmed cases were found from the active case finding measures. 


\subsection{Thai educational staff challenges}

The immediate need for an emergency remote teaching forced teacher educators to consume the numerous professional development opportunities provided to them by their institutions. Nevertheless, even more meaningful were the dozens of bottom-up professional learning communitiesthat emerged from the teachers themselves, with entire colleges becoming communities of practice [4].

Launching the new alternative initial teacher education programs during the Coronavirus crisis was a bold, proactive decision made by the ministry of education despite the vast public criticism. Policymakers at the Ministry trusted the teacher education colleges to handle such a program, given their successful functioning during the Covid-19 outbreak. The ability of the Thai teacher to face public criticism was also rooted in how they handled the teaching and learning during the Coronavirus pandemic.

While most alternative teacher education programs have emerged as a countermovement to traditional teacher education programs and their dissatisfaction [5], the current program was an attempt by the ministry seize an opportunity to recruit high-quality candidates into the education system. However, in a similar way to other alternative programs, this one also offered components which are missing in the traditional ones, such as transformative-oriented professional development [6], change of regularities in spaceand-time [7], on-the-job training [8], collaborative learning [9], and personalized learning [10]. All these components characterized the learning during the Coronavirus time.

In conclusion, the Coronavirus era led the Thai teacher education system, and particularly its staff members, to adapt to the 4th industrial revolution of the 21 st century [11]. The next challenge shortly is to fortify and maintain these achievements. Teacher education programs have to equip student teachers with the knowledge, tools, and resilience to cope effectively with upcoming education challenges such as those faced during the Covid-19 pandemic.

The COVID-19 pandemic will bring about many aspects for some parts of our carries on; our instruction and logical distributions are no particular case.

The new education solution must be taken near changes in the instructive way of thinking, such as dynamic as opposed to inactive learning. Besides, parts of gatherings that are difficult to measure, such as social collaboration and prosperity, introduction and conversation of exploration; hands-on educating; and the chance to travel and visit settings, regularly incorporate personal family time previously or after the gathering. The idea of crossbreed gatherings is one approach to join the advantages of face-to-face and virtual gatherings.

\subsection{The situation}

In quick succession, Thailand announced the closure of its schools and universities for a minimum of two weeks to contain the spread of the COVID-19 virus, which has been declared a global pandemic by the World Health Organization. Nevertheless, authorities in many of the countries acknowledge that closures could last much longer.

The closures came thick and fast this week after the number of cases began to rise several weeks after countries in North-East Asia, including Japan, South Korea, Singapore, and China - where the virus originated - closed their universities in February and March. Universities have yet to reopen in any region in the region, including Hong Kong and Taiwan.

Since the pandemic arises, Thailand on March 17 announced a two-week closure of all educational institutions until at least March 31 and so on. Thailand ministry of education Many faculties are switching very quickly to different learning methods following the 
covid19 outbreak. This crisis will make the institutions, which were earlier reluctant to change, to accept modern technology. This catastrophe will encourage educators to consider a different method of educating the student.

\section{Research Methodology}

This research applies a qualitative methodology, and the research team set up an in-depth interview with 28 experienced educational staff in Nakhon Pathom, Thailand, using snowball sampling during April 2020. Scope of information on the education obstacles, the challenges, and opportunities and how educational staff, teacher, lecturer in Nakhon Pathom, and Thailand respond to the disruptive impact of the COVID-19 pandemic. The data was analyzed using cause and effect analysis. The observed obstacles using the qualitative research methodology would be defined in the literature review section.

Table 2. Demographic characteristic of respondents.

\begin{tabular}{|l|l|c|c|}
\hline \multicolumn{2}{|l|}{ Demographic } & Frequency & Percentage \\
\hline Gender & Male & 15 & 53.571 \\
\hline \multirow{2}{*}{ Age } & Female & 13 & 46.429 \\
\hline & $16-30$ & 8 & 28.571 \\
\hline & $31-45$ & 14 & 50.000 \\
\hline Education & $46-60$ & 6 & 21.429 \\
\hline & Bachelor & 4 & 14.286 \\
\hline & Master Degree & 18 & 64.286 \\
\hline \multirow{5}{*}{$\begin{array}{l}\text { Teaching } \\
\text { Experience }\end{array}$} & Doctorate Degree & 6 & 21.429 \\
\hline Workplace & Between 0-10 Years & 11 & 39.286 \\
\cline { 2 - 4 } & Between 11-20 Years & 10 & 35.714 \\
\cline { 2 - 4 } & More than 20 years & 7 & 25.000 \\
\hline \multirow{3}{*}{ Level } & Government Institution & 18 & 64.286 \\
\hline & Private Institution & 10 & 35.714 \\
\hline & Primary/Secondary/High & 8 & 28.571 \\
\hline \multirow{2}{*}{$\begin{array}{l}\text { Total Students on } \\
\text { campus }\end{array}$} & School Teacher & 5 & 17.857 \\
\cline { 2 - 4 } & Vocational School & 15 & 53.571 \\
\cline { 2 - 4 } & University/Graduate School & 10 & 35.714 \\
\cline { 2 - 4 } & 100-500 & 11 & 39.286 \\
\hline \multirow{2}{*}{} & $500-1000$ & 7 & 25.000 \\
\hline
\end{tabular}

\section{Research Results}

The education obstacles due to the Covid19 pandemic:

\subsection{Educational staff social impacts}

As the whole education institution was closed due to the COVID-19, there is a parcel of individuals in Thailand alone recorded new unemployment claims in mid-2020. All the participants that work for all institutions confirm that the temporary contract staff is not terminated.The vast majority of Thai educational staff, despite everything, keeps their job. 
Be that as it may, the upcoming change may cause a scope of stress-related outcomes. The loss of social associations for the individuals who were laid off and those required to telecommute is a subtler effect of COVID-19; nonetheless, from research that excellent social connections - including casual talks among colleagues are fundamental for mental and physical wellbeing.

The majority of a social movement is never again polished. Against this scenery, both the prerequisite to work from home and plans to de-densify working environments on the side of physical separating are probably going to have reactions that incorporate probably some level of damage to people's psychological and physical wellbeing. Working environment depression has been appeared to have stable negative connections to representatives' full of feeling responsibility, affiliative practices, and execution. While we noticed that virtual interchanges need wealth, a more contrary danger of correspondences going on the web is that false impressions - without nonverbal signs - are probably going to build workers' interests about being relationally dismissed, which is a significant trigger for depression.

\subsection{Educational staff working impacts}

The government and institution policies significantly affecteducational staff attitudes and behaviors to their institutions and coworkers.

First of all, most educational staff are not prepared for online teaching activity, and in this circumstance, in many institutions, the full-time lecturer is not typical. Also, the cessation of face-to-face teaching activity looms as a threat to those teachers whose contracts focus exclusively on teaching complimentary classes, such as practical classes or seminars, and frequently part-time and considered an auxiliary or peripheral complement, if not included in students' options.

Online education is present in most institutions as an extension of the physical classroom. In practice, each educational staff's ability to continue teaching depends on their experience in that regard.

The subjects that incorporate the improvement of professional skills through training are a wellspring of more noteworthy vulnerability, which will prompt a lot of various effects on the arrangement of the individual college. Science, for the most part, presents more troubles in the virtual variation process. There are numerous educators who, not having past involvement with separation training and innovation have appropriated all the correspondence media available to them to create what has been called Emergency Remote Teaching which has been characterized as the way toward "changing the presential classes to a virtual model, yet without changing the educational plan or the approach." This would be like a condition experienced by the instructor or students when feeling overpowered by accepting unnecessary data through instructive stages, versatile applications, and email.

The expectation to absorb information for the effective utilization of innovation out yonder advanced education is exceptionally steep and requires outside help in the mechanical fields. This is where educators can see the contrast between those staff that make apparatuses and assets accessible to them.

\subsection{Institutional responses}

The new change in education modalityis a significant concern on the part of university leaders and the ministry of education.In the case of Nakhon Pathom, Thailand, most educational staff are convinced that retaining students to follow online courses isexceptionally problematic. Most of the educational staff are not experience conducting online teaching activities include prepare teaching outlines, teaching instruments for the 
visual classroom. The situation could negatively affectthe students who will no longer participate. Many participants admit that the change in modality was the result of an unforeseeableemergency and that they should start to plan for online teaching in the nextterm with more significant pedagogical support and resources, anticipating that the crisis's duration will extend beyond the term.

In dealing with the obstacles, adaptability is necessary to the situation that arises. When all teaching and learning cannot be done, difficulties in changing teaching and learning styles have been transmitted to educational staff. The problem with education is that the government was unable to support instructional staff promptly, a teacher in a public university added that: the university asked them to set up online teaching, but to do online teaching in the classroom that does not have supporting devices. The teaching equipment such as webcam and microphone used must be purchased themselves since withdrawing money in purchasing the teaching equipment must follow government procedures, which takes much time.

\subsection{Support in resources}

All participants realized, from the outset, that migrating to a virtual mode involved verysignificant risks of widening the effects of the digital divide by leaving unattendedthose students in whose homes there was no access to the quality of equipment orresources or connectivity, required in order to take advantage of adistance education offer supported by high technological components.

An increasing number of online classrooms have rolled out initiatives to support students who lackequipment by making available laptops or tablets temporarily. Also, therehas been an increase in the queues of students and teachers seeking technologicalsupport, particularly regarding the use of virtual platforms.

\section{Research Conclusions}

Concentrate on guaranteeing showing progression and ensuring value, making administration components, checking, and reasonable help. It might have appeared that one expected to change to a holding up mode until the resumption of classes. The way that up close and personal classes are bunch exercises will imply that, with regards to social separating measures, a repeat can be regular. The huge endeavors to adjust to new educating and learning modalities by educators and students likewise require that HEIs screen how encouraging exercises are done and what necessities can rise in the scholastic network. It is in this manner valuable to:

- Establish an emergency board to concentrate basically on coherence and value, fusing specialized and academic components, and be the voice of the fundamental entertainers;

- Monitor and give daily follow-up on the necessities that emerge for each situation;

- Address need issues of the absence of teaching equipment or availability, and beyond what many would consider possible, offer administrations and applications for mobile phones; and

- Guarantee that students and instructors have perpetual helplines, either by phone or the web.

Advance inner reflection on the restoration of the educating and learning model.

Finally, the instructive staff will have ruined an extraordinary chance on the off chance that they do not stop to reflectinside, with understudy's and instructors' cooperation, about the exercises masteredduring the emergency about the educating and learning forms. The essential inquiry iswhether the gained experience can be promoted for an update of these 
procedures, augmenting the upsides of up close and personal classes while benefiting as much as possible from innovations.

Every crisis, there is always an opportunity. Perhaps, in thiscase, it is an opportunity for a pedagogical review. Therefore, it is expected that much educational staff will undertake the path of a necessary pedagogical renewal that favors bothquality and equality.

Learn from mistakes and scale-up digitization, hybridization and ubiquitous learning.

Many institutions have made the mistake of relying exclusively on online education,which ensures continuity of learning opportunities for students with accessto functional connectivity. Resorting to technologies that require stable bandwidthconnectivity significantly impacts the more vulnerable sectors. Internet access is notalways possible, and when it is, connectivity is often lacking. The classes that aretransmitted using streaming, for example, are more difficult to access due to theamount of data they use and the quality of connectivity required. In this sense,virtualization particularly impacts socially and economically disadvantaged studentswho have only recently benefited from the processes of democratization and massenrollment in higher education.

If virtualization is the primary tool to sustain theeducation function, the enormous digital divide must be considered. Itsexistence must be recognized, not to reject virtualization but todesign strategies and support mechanisms that will help combat it even moreintensely.

It is necessary to start from the principle of realismand generate strategies that do not rely only on a single technology, but on several toensure that all students are taken into account or, which is equally or morecritical, that technological solutions do not harm those who are already disadvantaged.

\section{Recommendations for Future Research}

The further researches should focus on what factors will lead to helping and prosocial behaviors in teams with either low or high virtually - and how will these impact outcomes?

\section{Acknowledgments}

The researchers would like toexpress my special appreciation and thanks to the Research and Development Institute, SuanSunandhaRajabhat University, Bangkok, Thailand and Rajamangala University of Technology Rattanakosin, Bangkok, Thailand for academic support.

\section{References}

1. A. Privara, Transnational Marketing Journal 7(1), 59-72 (2019)

2. T. Isaeva, The EUrASEANs: Journal on Global Socio-Economic Dynamics 1(1), 61-68 (2016)

3. A. Privara, M. Privarova, Sustainability 11, 5586 (2019)

4. E. Wenger, Communities of Practice: Learning, Meaning, and Identity (Cambridge, Cambridge university press, 1998)

5. L. Darling-Hammond, Educational Researcher 45(2), 83-91 (2016)

6. A. Kennedy, Professional Development in Education 40(5), 688-697 (2014)

7. A. Privara, Migration Letters 16(2), 245-254 (2019)

8. R. Guha, M.E. Hyler, L. Darling-Hammond, American Educator 41(1), 31-34 (2017) 
9. D. Chicoine, Educational Studies 36(3), 245-263 (2004)

10. C. Gamrat, H.T. Zimmerman, K. Peck, British Journal of Educational Technology 45(6), 1136-1148 (2014)

11. A. Hussin, International J. of Education and Literacy Studies 6(3), 92-98 (2018)

12. A. Privara, Geographical Journal 71(2), 161-180 (2019) 